\title{
LOS NUEVOS PARADIGMAS ECONÓMICOS Y TECNOLÓGICOS EN LA ACTIVIDAD TURÍSTICA Y SU RELACIÓN CON EL AMBIENTE
}

\section{THE NEW ECONOMIC AND TECHNOLOGICAL PARADIGMS IN TOURISM ACTIVITY AND ITS RELATIONSHIP WITH THE ENVIRONMENT}

\author{
Liliana María Dieckow \\ Facultad de Humanidades y Ciencias Sociales \\ Universidad Nacional del Misiones \\ Posadas, Misiones, Argentina \\ lilianadie@gmail.com
}

Fecha de recepción: 18/09/20 - Fecha de revisión: 09/10/20 - Fecha de aprobación: 15/01/21

DOI: https://doi.org/10.36995/j.visiondefuturo.2021.25.02.006.es

\section{RESUMEN}

Este artículo presenta resultados de la tarea docente - investigativa sobre el nuevo paradigma económico y las nuevas formas de comunicar, comercializar, vender y consumir en turismo. Este nuevo paradigma económico relacionado con la tercer o -según autores- la cuarta revolución industrial que considera al pro - común colaborativo, la reducción de los costos marginales cercano a cero, las nuevas energías sustentables y el internet de las cosas. A ello se le suman las nuevas Generaciones de personas, los Millennials y los Centennials con motivaciones, emociones y comportamientos particulares para sus experiencias de viajes, muy conectados a redes sociales y a las tecnologías, que llevan a reconfigurar la actividad económica del turismo desde sus bases. Incluso se habla del surgimiento de nuevos verbos asociados al uso de la tecnología por parte de estas generaciones. Nuevas plataformas de búsqueda y portales de compras como Booking, y agencias online como Despegar, que se imponen en el mercado. Ante estos cambios de escenario y de demanda, las empresas deben adaptarse a esta nueva economía y bases tecnológicas, redefiniendo su forma de conectarse con sus potenciales clientes y su forma de desarrollar la actividad turística de forma más sustentable, más activa y menos masiva.

PALABRAS CLAVE: Turismo; Nuevo paradigma económico; Nuevas tecnologías; Actividad sustentable.

\section{ABSTRACT}

This article presents results of the teaching-research task on the new economic paradigm and the new ways of communicating, marketing, selling and consuming in tourism. This new economic paradigm related to the third or -according to authors- the fourth industrial

\footnotetext{
"Visión de Futuro" Año 18, Volumen N²5 N², Edición Especial-III Congreso Regional de Economía del Norte Grande-Pág 124-144 URL de la Revista: http://visiondefuturo.fce.unam.edu.ar/index.php/visiondefuturo/index URL del Documento: https://visiondefuturo.fce.unam.edu.ar/index.php/visiondefuturo/issue/view/20 ISSN 1668 - 8708 - Versión en Línea E-mail: revistacientifica@fce.unam.edu.ar

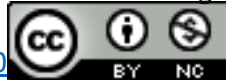


revolution that considers the collaborative common, the reduction of marginal costs closes to zero, the new sustainable energies and the internet of things. Added to this are the new Generations of people, Millennials and Centennials with particular motivations, emotions and behaviors for their travel experiences, closely connected to social networks and technologies, which lead to reconfigure the economic activity of tourism from its bases. There is even talk of the emergence of new verbs associated with the use of technology by these generations. New search platforms and shopping portals such as Booking, and online agencies such as Despegar, which are imposed on the market. Faced with these changes in scenario and demand, companies must adapt to this new economy and technological bases, redefining their way of connecting with their potential customers and their way of developing tourism in a more sustainable, active and less massive way.

KEY WORDS: Tourism; New economic paradigm; New technologies; Sustainable activity.

\section{INTRODUCCIÓN}

En los últimos años se observan cambios vertiginosos en lo referente a la ciencia y tecnológica. En este sentido, el autor argentino Santiago Bilinkis (2014) destaca la Ley de (Gordon) Moore, la cual sostiene que aproximadamente cada dos años se duplica el número de transistores en un microprocesador, estamos ante cambios cada vez más frecuentes y vertiginosos en materia tecnológica. Así - en base a Thomas Kuhn - se habla de nuevos paradigmas económicos y tecnológicos los cuales afectan a todas las actividades productivas y en particular al turismo. Por otra parte, estamos con nuevas generaciones de personas como los Millennials (Generación Y) y Centennials (Generación Z), quienes tienen motivaciones e intereses propios y diferentes a generaciones previas.

En función de ello, este artículo presenta resultados parciales de las tareas docentes en la cátedra Problemática Económica del Turismo (del cuarto año de la Licenciatura en turismo de la UNaM) y del proyecto de investigación (PDTS) titulado LOS MILLENNIALS Y EL TURISMO. Análisis de las particularidades de esta generación en relación al consumo turístico, su percepción sobre la calidad, y su desempeño como profesional, en función de su formación, inserción laboral y Emprendedurismo (Código 16H/493).

Las preguntas que orientan este artículo son: ¿Cómo se relacionan la Tercer Revolución Industrial con las dos últimas generaciones de personas y el turismo? ¿Qué cambio de paradigma económico y tecnológico generan? ¿Qué importancia otorgan estas nuevas generaciones al ambiente y a la tecnología? ¿Cómo deben adaptarse las empresas ante este nuevo escenario?

\footnotetext{
"Visión de Futuro" Año 18, Volumen No 25 N², Edición Especial-III Congreso Regional de Economía del Norte Grande-Pág 124-144 URL de la Revista: http://visiondefuturo.fce.unam.edu.ar/index.php/visiondefuturo/index

URL del Documento: https://visiondefuturo.fce.unam.edu.ar/index.php/visiondefuturo/issue/view/20

ISSN 1668 - 8708 - Versión en Línea

E-mail: revistacientifica@fce.unam.edu.ar
} 
En función de estas preguntas, este trabajo se propone analizar la Tercer Revolución Industrial en función del cambio de paradigma económico-tecnológico que genera y su relación con los Millennials y Centennials, en cuanto a su valoración de la tecnología y ambiente en la actividad turística. Como objetivos específicos se busca: 1. Analizar las particularidades de la Tercer Revolución Industrial y su cambio de paradigmas económico y tecnológico. 2. Analizar los cambios de las motivaciones, emociones y comportamiento de las generaciones Millennials y Centennials ante los viajes. 3. Analizar las adaptaciones necesarias en las empresas para atender a estas nuevas necesidades y deseos de los Millennials y Centennials.

\section{DESARROLLO}

\section{Breve revisión de antecedentes}

\section{La Tercer Revolución industrial y el nuevo paradigma económico y tecnológico}

Para comenzar, es necesario recordar que la Humanidad ha pasado por varios momentos que han significado rupturas económicas, tecnológicas, sociales y políticas, conocidas como Revoluciones industriales, debido a que la industria - bajo sus diferentes formas - ha sido el motor de estos cambios.

Así, la Primera Revolución Industrial (entre los años 1.750 y 1.870 aproximadamente) se caracterizó por el uso del carbón (ferrocarril y fábricas) y el telégrafo, que permitieron generar las primeras ciudades grandes. La Segunda Revolución Industrial (entre los años 1.850 y 1.970 aproximadamente), caracterizada por el uso de los combustibles fósiles como el petróleo (que se está agotando y que se evidencia en la caída del PBI global), el uso de automóviles, nuevos medios de comunicación como la telefonía, la radio y la televisión que aceleraron las sub urbanizaciones y las desigualdades entre países. Actualmente, participamos de la Tercera Revolución Industrial o Revolución científico - tecnológica (desde el año 2.006 en adelante), en la que - según Jeremy Rifkin - aparece un sistema económico nuevo que es el procomún colaborativo. Si bien esta Tercer Revolución Industrial se basa en nuevas Tecnológicas de la Información y Comunicación (TIC y NTICS) y el uso civil de internet (que se convertirá en el sistema nervioso de esta revolución), el transporte verde, el uso de energía renovable como el sol, el viento, las olas, entre otras, pero como sostiene Rifkin (2011) lo más destacado de esta revolución es el procomún colaborativo, que está cambiando la vida económica y puede ofrecer la posibilidad de democratizar la economía y reducir las diferencias de ingresos y crear una sociedad más sostenible desde el punto de vista ecológico.

\footnotetext{
"Visión de Futuro" Año 18, Volumen No 25 №2, Edición Especial-III Congreso Regional de Economía del Norte Grande-Pág 124-144 URL de la Revista: http://visiondefuturo.fce.unam.edu.ar/index.php/visiondefuturo/index

URL del Documento: https://visiondefuturo.fce.unam.edu.ar/index.php/visiondefuturo/issue/view/20

ISSN 1668 - 8708 - Versión en Línea

E-mail: revistacientifica@fce.unam.edu.ar
} 
Al considerar prioritario el procomún colaborativo, por primera vez se plantea y mira la revolución desde el lado de la demanda.

Para Rifkin (2014) la Tercera Revolución Industrial está generando un cambio en el paradigma económico, produciéndose el primer cambio de fondo en la vida económica desde la aparición del capitalismo y el socialismo a principios del siglo XIX, formándose una economía híbrida en la que coexisten y se colaboran mutuamente las dos economías, la capitalista tradicional y la del procomún colaborativo. Destaca este autor que el capitalismo se basa en trasformar todas las cosas en mercancías (algo con valor económico), que se intercambian en el mercado como una propiedad, con precio, argumentando su condición de escasez de oferta y necesidad ilimitada de la demanda, producida y por ello con costos. Si nos basáramos en Adam Smith, diría que el mercado actual se comporta de manera muy parecida a como actúa la ley de gravedad de Newton, a cada acción hay una reacción contraria equivalente y así la oferta y la demanda se equilibran en un mercado autorregulado, de lo contrario habrá subas de precios o caída en la cantidad ofrecida o demandada. Por su parte, Jean Bautista Say decía que la actividad económica se auto perpetúa por el movimiento constante generado una vez iniciada la actividad económica, por lo que la creación de un producto abre inmediatamente un mercado para más producción y nuevos productos. La tecnología surge para incrementar la productividad y vender a precios más bajos en un mercado competitivo. Aunque ante situaciones de monopolio esto es diferente, para estos autores siempre surgirán nuevos competidores que romperán el monopolio u oligopolio. Esta tecnología permite producir más y bajar los costos. Entonces Rifkin (2014) se pregunta: ¿hasta qué nivel puede bajar los costos marginales?, ¿qué consecuencias traería si alcanza niveles cercanos a cero? Keynes ya analizaba este tema en la década del 30 acuñando el término desempleo tecnológico. Además, John Maynard Keynes destacaba que es natural que, en el dinamismo empresarial, propio de los mercados competitivos, se aumente la productividad y reduzcan los costes marginales. Por su parte, a principios del siglo XX Oskar Lange decía que cuando un empresario incorporaba tecnología para reducir costos, obtenía en un corto plazo una ventaja competitiva frente a los competidores que tenían un medio de producción anticuado, pero, que pronto los competidores harían lo mismo y se daría un círculo virtuoso. No obstante, en general, las empresas más poderosas tratarían de evitar la incorporación de nuevas empresas e innovaciones al mercado y ello muchas veces produce estancamiento en el corto plazo.

Para Rifkin (2014), el capitalismo seguirá existiendo, pero desempeñará un papel cada vez más especializado y señala, sobre todo, que estamos entrando en un mundo que, en

\footnotetext{
"Visión de Futuro" Año 18, Volumen No 25 N², Edición Especial-III Congreso Regional de Economía del Norte Grande-Pág 124-144 URL de la Revista: http://visiondefuturo.fce.unam.edu.ar/index.php/visiondefuturo/index

URL del Documento: https://visiondefuturo.fce.unam.edu.ar/index.php/visiondefuturo/issue/view/20

ISSN 1668 - 8708 - Versión en Línea

E-mail: revistacientifica@fce.unam.edu.ar
} 
parte, se encuentra más allá de los mercados, en el que aprendemos a convivir en un procomún colaborativo mundial cada vez más interdependiente.

En ese sentido, el autor argentino Santiago Bilinkis (2014) destaca que el ritmo de los cambios es cada vez más acelerado, al que estamos expuestos hoy respecto a décadas atrás y en el futuro va a acelerarse mucho más aún. Asimismo, los avances de las disciplinas como la biología artificial (desde que se descifró el ADN humano a la creación de vida artificial), las neurociencias y la Inteligencia Artificial (IA); destacan cambios mucho más profundos y radicales.

Los aportes del factor de producción Conocimiento $(C)$ más allá de los tres factores de producción tradicionales que son Tierra, trabajo y capital, compuesto por datos e información ubicua (tiempo, formas y lugar adecuados), la innovación y -para el autor argentino Andy Freire (2015) - el emprendedurismo en los inicios del siglo XXI, serían determinantes para el desarrollo económico de los países.

Con esta Tercer Revolución Industrial o Revolución científico - tecnológica, Rifkin (2014) dice que estamos ante un nuevo paradigma económico que daría lugar a: a) Las nuevas energías que son utilizadas para producir, que contaminan menos y diversifican su tipo y fuente de generación. Así, cada vivienda o edificio podría generar energía solar, eólica, etc., b) El Internet de las Cosas (IdC) o Internet de todo. Santiago Bilinkis (2014) plantea que el concepto de $\mathrm{IdC}$ se refiere a la transformación que surge cuando los objetos y aparatos ganan en autonomía y dialogan entre sí. Para Rifkin (2014) el IdC combina Internet de las comunicaciones (comunicación más accesible) con Internet de la energía que lleva la producción a un Costo Marginal $(\mathrm{CMg}$ ) cercano a cero e Internet de la logística (bases de datos) y hace que lentamente estemos pasando de la economía de la escasez la economía de la abundancia. EI IdC conectará todas las cosas con todas las personas en una red integrada mundial. Un ejemplo concreto son los sensores industriales que favorecen la trazabilidad y manejo de residuos urbanos que permiten ciudades inteligentes; en los bosques, monitorear animales, erupciones, incendios; del cuerpo humano; meteorológicos, entre otros. El IdC convierte a cada persona en un Pro - sumidor (una persona que consume y aconseja y produce al mismo tiempo). Si bien aún estamos lejos de alcanzar la plenitud del IdC, cada vez hay más señales de que estamos en camino a ello, indicado, por ejemplo, por el alza de valor de las acciones de empresas relacionadas al tema. c) El pro-común colaborativo se relaciona con la Economía Colaborativa (EC). El Pro-común precede al capitalismo (está presente desde los hombres paleolíticos y tuvo gran auge en la Edad Media con el pro-común feudal) y al Estado representativo y es la forma más antigua de actividad auto - gestionada. Hoy se lo conoce como Pro-común social y lo vemos reflejado en

\footnotetext{
"Visión de Futuro" Año 18, Volumen No 25 N², Edición Especial-III Congreso Regional de Economía del Norte Grande-Pág 124-144 URL de la Revista: http://visiondefuturo.fce.unam.edu.ar/index.php/visiondefuturo/index

URL del Documento: https://visiondefuturo.fce.unam.edu.ar/index.php/visiondefuturo/issue/view/20

ISSN 1668 - 8708 - Versión en Línea

E-mail: revistacientifica@fce.unam.edu.ar
} 
organizaciones auto - gestionadas de carácter religioso, cultural, deportivo, profesional, cooperativas, asociaciones de vecinos, grupos de apoyo, conocidos como sector no lucrativo o sociedad civil. Se orientan más a colaborar o compartir que a intercambiar cosas.

Como dato curioso, el término Colaborativo recién surge a mediados del siglo XX. Para Rifkin (2014) estos pro común comparten información, entretenimiento, energía, productos impresos en impresoras 3D y cursos - publicaciones con un coste marginal cercano a cero y otras cosas como automóviles, alojamientos, prendas de vestir, clubes, redes sociales, asistencia sanitaria, cuidado del ambiente, entre otros. Para algunos autores, tanto Uber (transporte), Airbnb y Courchsurfing (en alojamientos) no son realmente opciones de economía colaborativa sino servicios sustitutos, ya que, en los mismos, se intermedia a través de dinero y prestación de servicios y no son de intercambio como lo hacen, por ejemplo, las ferias americanas.

Hugo Kuklinski (2017) destaca que otros autores, como Paul Mason (2015) también coinciden con Rifkin al señalar que en el corazón del cambio del capitalismo están las tecnologías de la información y su capacidad de colocar a costo (o precio) cero muchas de los bienes que los seres humanos realizamos e intercambiamos, así como reducir al máximo los costos de hardware, software y conectividad. Para Mason, el capitalismo está mutando hacia una cosa completamente nueva y que ello nos llevará hacia un modelo mucho más sustentable y social, y que aún somos capaces de configurarlo para que así suceda. (http://digitalismo.com)

Puntualmente, la Economía Colaborativa, es definida por Cañigueral Bagó como "la manera tradicional de compartir, intercambiar, prestar, alquilar y/o regalar es re - definida a través de la tecnología y las comunidades" (Dieckow y Lansse, 2017, p. 42). La misma está muy presente en la actividad turística, ya que ella viene experimentando drásticos cambios en los últimos años. En este sentido, la EC se ha convertido en una de las principales tendencias turísticas del siglo XXI. Irrumpe al inicio del nuevo milenio en los Estados Unidos y a raíz de la crisis económica (2008) se populariza en Europa, la búsqueda de precios baratos, la centralidad de Internet, la desintermediación y las motivaciones vacacionales.

En relación al turismo, Airbnb (alquiler de habitaciones a viajeros) se define como un mercado comunitario que ofrece una plataforma por Internet o mercado online, que conecta a anfitriones que tienen alojamiento para alquilar con clientes que buscan alquilar dichos alojamientos. Fundado en el año 2008 (San Francisco - California) como una iniciativa de dos jóvenes emprendedores universitarios, hasta consolidarse como uno de los modelos de negocio más disruptivo en el ámbito del sector turístico a escala internacional y constituyendo uno de los ejemplos de éxito de los llamados negocios Peer-to-Peer (P2P). Esta empresa

\footnotetext{
"Visión de Futuro" Año 18, Volumen N²5 N², Edición Especial-III Congreso Regional de Economía del Norte Grande-Pág 124-144 URL de la Revista: http://visiondefuturo.fce.unam.edu.ar/index.php/visiondefuturo/index

URL del Documento: https://visiondefuturo.fce.unam.edu.ar/index.php/visiondefuturo/issue/view/20

ISSN 1668 - 8708 - Versión en Línea

E-mail: revistacientifica@fce.unam.edu.ar
} 
ofrece a sus usuarios experiencias únicas y está presente en 34.000 ciudades y 191 países con más de 60 millones de huéspedes y cubre alrededor de 2 millones anuncios en todo el mundo (AIRBNB, 07/04/17). Puntualmente en la provincia de Misiones, la web permite identificar más de 180 anfitriones de Airbnb, lo cual indica que es un caso que está en una etapa de gestación (AIRDNA, 17/04/2016). Este servicio de alojamiento supera en muchos destinos turísticos a la cantidad de plazas del alojamiento tradicional hotelero y por lo que resulta muy cuestionado (como competencia desleal), debido a que no está legislado en muchos países como la Argentina.

Otro ejemplo son las guías turísticas como Trip4real, es la nueva y revolucionaria manera de viajar y disfrutar, se aparta de las ofertas turísticas masivas y descubre el destino a través de actividades únicas realizadas por la gente local que hace de guía. En la ciudad de Barcelona (España) cuenta con mayor popularidad, se inició en el año 2014 y actualmente tienen 2.000 actividades publicadas, mientras otras ciudades como Londres (150 actividades), Ámsterdam (100 actividades), París (200 actividades), Lisboa (300 actividades), todos ellos surgieron en el año 2015 como señala el Barómetro sobre Economía Colaborativa en el sector turístico.

Respecto al transporte, el caso de SocialCar, en España existe desde el año 2011, es la plataforma líder en alquiler de vehículos entre particulares. Esta permite a personas particulares ofrecer sus vehículos en alquiler a otros conductores registrados. También tienen resuelta la cuestión del seguro que en algunos países todavía es una deuda pendiente.

Otro ejemplo es Uber, una empresa internacional que ofrece al público una red de transporte con características únicas. Funciona mediante una aplicación propia, obligatoria tanto para el conductor como para el pasajero, de esta forma conecta ambas partes a través de sus dispositivos móviles. Esta empresa funciona desde el año 2009 y actualmente se encuentra en más de 400 ciudades del mundo, llegando a la Argentina. en el año 2016. Lo atractivo que tiene este tipo de servicio es que es más barato en un $35 \%$ respecto del taxi (UBER, 17/04/16)

Todavía falta mucho en lo que respecta a la legislación de este tipo de servicios, para poder encuadrarse en un marco normativo y que permita operar en un ámbito de legalidad e igualdad de condiciones en los otros oferentes. Habrá mucho por trabajar entre los gobiernos, economías tradicionales y estas nuevas formas a las que llamamos Economía colaborativa. Sin embargo, su crecimiento es vertiginoso y es cada vez más frecuente y variado.

También debe tenerse en cuenta que esta nueva Revolución industrial trae consigo beneficiada por las TIC e internet- nuevos conceptos y herramientas científico- tecnológicos como la geolocalización, el Big Data, la robótica combinada con la Inteligencia Artificial, los

\footnotetext{
"Visión de Futuro" Año 18, Volumen N²5 N², Edición Especial-III Congreso Regional de Economía del Norte Grande-Pág 124-144 URL de la Revista: http://visiondefuturo.fce.unam.edu.ar/index.php/visiondefuturo/index

URL del Documento: https://visiondefuturo.fce.unam.edu.ar/index.php/visiondefuturo/issue/view/20

ISSN 1668 - 8708 - Versión en Línea

E-mail: revistacientifica@fce.unam.edu.ar
} 
Boots (asistentes virtuales), la Realidad Aumentada (RA), la Realidad Virtual (RV) y el Marketing Omnicanal (muchos canales), que van generando en el sector turístico el uso cada vez más frecuente del término Smart (inteligente) que es aplicado a ciudades y destinos turísticos, los cuales apuntan a una mayor eficiencia en el uso de recursos y al logro de sustentabilidad. Como ejemplos de destinos turísticos inteligentes basta recordar en España a Benidorm (certificado) y la Red Argentina de destinos turísticos inteligentes, compuesta por 128 municipios, que se basan en el Big data, la innovación, la sostenibilidad, la accesibilidad y las TIC.

\section{Las Generaciones Millennials y Centennials}

Las revoluciones industriales han colaborado para que los grupos de personas cambien sus motivaciones, intereses, aspiraciones, entre otras cosas. Así, surge el concepto de Generaciones, que hace alusión a individuos que vivieron en un mismo periodo histórico y cuya edad es equivalente. Así, existen diferencias marcadas entre una y otra generación; las cuales están dadas por su relación con la tecnología, sus hábitos de consumo, gustos, relación con el trabajo y su concepción de las relaciones sociales.

Como todo cambia, las generaciones de personas también cambian. Así, se habla de las últimas tres generaciones $(\mathrm{X}, \mathrm{Y}, \mathrm{Z})$. A continuación, se presenta el perfil de las generaciones según la bibliografía internacional.

La Generación X (corresponde a personas nacidas entre los años 1965 - 1981) que se caracterizan por:

- Vida analógica en su infancia y digital en su madurez.

- Vivieron la llegada de Internet.

- Acepta las reglas de la tecnología y conectividad.

- No logra desprenderse del todo de las culturas organizacionales.

- Les interesa tener bienes materiales.

- Es la generación de la transición, pero con mayor fricción con las que vienen (Y, Z).

Luego, la Generación Y (nacidos entre los años 1982 - 1994) o Millennials, que se caracterizan por:

- Son la mayor proporción de consumidores de turismo actualmente.

- Son multitareas.

- No conciben la realidad sin tecnología.

- La calidad de vida tiene prioridad ante los bienes materiales.

- Son emprendedores.

\footnotetext{
"Visión de Futuro" Año 18, Volumen No 25 N², Edición Especial-III Congreso Regional de Economía del Norte Grande-Pág 124-144 URL de la Revista: http://visiondefuturo.fce.unam.edu.ar/index.php/visiondefuturo/index

URL del Documento: https://visiondefuturo.fce.unam.edu.ar/index.php/visiondefuturo/issue/view/20

ISSN 1668 - 8708 - Versión en Línea

E-mail: revistacientifica@fce.unam.edu.ar
} 
- Es la generación que usó más tipos de tecnología para entretenimiento: Internet, SMS, Reproductor de CD, MP3, MP4, DVD entre otros.

- Lo que era un lujo para la generación X para la generación Y son productos básicos.

- Eligen ofertas de la Economía colaborativa.

Finalmente, la Generación Z (nacidos entre los años 1995 y la actualidad) o también conocidos como Centennials o nativos digitales, se caracterizan por:

- Recién están ingresando al mundo laboral.

- Poseen alta propensión al consumo.

- Tienen acceso y manejo a toda su tecnología: Internet, mensajes instantáneos, SMS, celulares, iPod, iPad, Notebook, etc.

- Ven la tecnología como elemento fundamental (no conciben el acceso a la información sin la existencia de Google).

- Sus medios de comunicación utilizados principalmente son redes sociales.

- Profundizan los entornos virtuales.

- Consumen turismo, pero con sus propios intereses.

- Eligen ofertas de la Economía colaborativa (Dieckow y Lansse, 2017, p. 74-75)

Para la Revista Forbes (2017), las personas que forman parte de la Generación Millennials son: a- Digitales (prefieren Internet a la TV convencional). b- Multipantalla y multidispositivo, con capacidad (o necesidad) de hacer varias cosas a la vez. c- Nomófobos y appdictos (teléfono móvil y aplicaciones). d- Sociales (consultar, compartir y comentar en redes sociales y aplicaciones, son las principales actividades que realizan a través de sus teléfonos inteligentes). e- Críticos y exigentes (los negocios ya no son solo servicios y productos, son también relaciones y la experiencia de compra es tan relevante como el propio producto). f- Exigen personalización y nuevos valores (son clientes que no buscan exclusivamente una buena atención, sino que exigen personalización y esperan que la empresa se adecue a sus preferencias)

En cuanto a las características de la Generación Millennials, Andrés Hatum (2013), sostiene que la Generación Y, Generación.com (por sus capacidades naturales de manejar tecnología), Generación next según Howe y Strauss o generación del milenio, puede ser definida como un grupo de personas nacidas entre los años 1981 y 1997, con las siguientes características genéricas: son ensimismados, desconfiados, despreocupados por las reglas y superficiales. Por su parte, Lee Caraher (2016) considera que son falsos los mitos de que los Millennials son engreídos, que no trabajan duro o que son inestables en el trabajo, aunque reconoce en parte que son informales y que buscan la flexibilidad en el trabajo. Hatum (2013)

\footnotetext{
"Visión de Futuro" Año 18, Volumen N²5 N², Edición Especial-III Congreso Regional de Economía del Norte Grande-Pág 124-144 URL de la Revista: http://visiondefuturo.fce.unam.edu.ar/index.php/visiondefuturo/index

URL del Documento: https://visiondefuturo.fce.unam.edu.ar/index.php/visiondefuturo/issue/view/20

ISSN 1668 - 8708 - Versión en Línea

E-mail: revistacientifica@fce.unam.edu.ar
} 
también los considera realistas y con ciertos valores que impulsan su conducta, actitud e intereses como la multiplicidad de tareas (ya que han sido sobre estimulados desde niños), el importante papel de la tecnología en sus vidas y estar conectados (caracterizada por el uso de redes sociales e internet en general, además de los teléfonos celulares), buscan integrar trabajo - vida y no solo equilibrarlos, además de la conciencia social (buscando lugares de trabajo que respondan a los problemas sociales y ambientales), características que a la vez impactarán en el ámbito laboral y las organizaciones en general. Es una generación multitarea, pero, que se distrae con mucha facilidad, por lo que las empresas - así como el sistema educativo - deben cambiar de estrategias para captar su atención. Asimismo, se dicen que son auténticos y poco apegados a sus puestos de trabajo.

\section{Daniela Mora Simoes dice}

"Que parte de esta generación es hija de los Baby Boomers, sienten que pueden hacer cosas y transformar el mundo, pero también aprendieron de la generación $\mathrm{X}$ no tener confianza ilimitada; son, ante todo pragmáticos. Crecieron opinando y valoran la diversidad y el respeto por las diferencias... son y quieren ser vistos como adultos, pero manteniendo espacios y prácticas infantiles" (Mora Simoes D, 2017, p. 29)

No todas las personas de la Generación Millennials son iguales, ya que hay diferencias entre los lugares de residencia o nacimiento (por su acceso a la tecnología e internet) y según el año exacto de su nacimiento. Lee Caraher lo ejemplifica:

"Para el territorio de los Estados Unidos, se dice que quienes nacieron entre 1980 y 1986 llegaron a su cuna durante una gran recesión y los que llegaron más tarde, algunos aún están estudiando" (Caraher L, 2016, p. 27)

\section{Para Oscar Hidalgo, los Millennials}

"poseen características que los hacen únicos en comparación con las generaciones anteriores; se encuentran entre dos mundos que conocen a la perfección: el mundo tecnológico y el tradicional. Consideran a la tecnología como herramienta natural en el quehacer diario, el internet, el celular y las tabletas, entre otros. Las redes sociales fueron inventadas por ellos y son su forma de vida: están descontentos y son incrédulos, tienden a confiar menos en las personas que las generaciones anteriores, se declaran independientes y forman el grupo con mayor descontento político y religioso...Tienen un nivel de estudios bastante superior. Su situación social es compleja, se los conoce como la generación Boomerang; han tenido que volver a su casa de crianza y atrasar la formación de su propio hogar o familia por encontrar un trabajo que los apasione y lograr total independencia...En su mayoría, la generación del milenio espera trabajar en seis o más compañías a lo largo de su vida. Casi la mitad del grupo económicamente activo perteneciente a la Generación Millennials contestó a Deliotte que quieren cambiar de empleos en los próximos dos años para buscar mejores y más beneficios." (Hidalgo H, 2020)

Por su parte, el término Centennial fue acuñado en 2015 por la consultora de Kantar Group, para diferenciar a los adolescentes que habían nacido en plena eclosión digital,

\footnotetext{
"Visión de Futuro" Año 18, Volumen No 25 N², Edición Especial-III Congreso Regional de Economía del Norte Grande-Pág 124-144 URL de la Revista: http://visiondefuturo.fce.unam.edu.ar/index.php/visiondefuturo/index

URL del Documento: https://visiondefuturo.fce.unam.edu.ar/index.php/visiondefuturo/issue/view/20

ISSN 1668 - 8708 - Versión en Línea

E-mail: revistacientifica@fce.unam.edu.ar
} 
concretamente entre los años 1994 y 2009. Hasta ese momento eran conocidos como la Generación Z a quienes seguían después de la Generación Y (Millennials) y la Generación X.

Si bien tienen varios elementos comunes con los Millennials (ambos son nativos digitales), los Centennials, a diferencia de los anteriores, no conocen la vida sin smartphones o Internet, y esto influye mucho en la manera en la que ven su existencia y también en su modo de consumir productos y servicios. La consultora Atrevia y Deusto Business School los describen como la primera generación que ha incorporado Internet en las fases más tempranas de su aprendizaje y socialización, les gusta aprender por su cuenta, son creativos, innovadores y están sobreexpuestos a la información, son incapaces de interactuar en un mundo sin pantalla; hasta se podría decir que las pantallas son extensiones de sí mismo. Han crecido sobreexpuestos a la información, y quizá por eso están más conectados a la realidad y son menos ambiciosos y soñadores que los Millennials. Las compras online y las reviews de otros usuarios influyen bastante más en esta generación que en el caso de los Millennials. La capacidad de atención de los Millennials es de 12 segundos, mientras que la de los Centennials se reduce a los 8 segundos. Están habituados a la sobrecarga sensorial al manejar varias pantallas al mismo tiempo (smartphone, tablet, portátil, etcétera) por lo que necesitan menos tiempo para filtrar los estímulos o información que les llega. Para los Centennials es la herramienta única que facilita el acceso a la comunicación, la educación o el entretenimiento, gracias a su condición de especialistas digitales. El 75\% de los Centennials funcionan como influenciadores o Influencers de sus casas a la hora de tomar decisiones importantes referidas al gasto familiar. Cada vez es más habitual que las familias pidan consejos a los miembros más jóvenes para recopilar información o comparar reviews sobre productos. Esta tendencia se materializa mejor en artículos de alimentación y bebidas (77\%), muebles $(76 \%)$ y productos del hogar (73\%). "Tienden más a compartir sus propias imágenes y en ese sentido, se identifican más con Instagram que con otras plataformas como Facebook o Twitter. Perciben a las marcas como concepto y se preocupan, sobre todo, de las marcas que, de algún modo, encajan y se adaptan perfectamente a sus vidas y les conectan a las cosas que realmente les importan" (https://marketing4ecommerce.net)

Debe destacarse que - en términos generales - hay nuevas tendencias de demanda, que surgen de nuevas necesidades y motivaciones. El autor y empresario español Eulogio Bordas plantea que estamos pasando de la Pirámide de Necesidades (de Abraham Maslow) a una Pirámide Emocional, donde los valores (lo natural, la autenticidad, el contacto, la experiencia, las emociones, los recuerdos) son lo más importante, pasando de una Sociedad de la información a la Sociedad de ensueño (https://www.uoc.edu).

\footnotetext{
"Visión de Futuro" Año 18, Volumen No 25 N², Edición Especial-III Congreso Regional de Economía del Norte Grande-Pág 124-144 URL de la Revista: http://visiondefuturo.fce.unam.edu.ar/index.php/visiondefuturo/index

URL del Documento: https://visiondefuturo.fce.unam.edu.ar/index.php/visiondefuturo/issue/view/20

ISSN 1668 - 8708 - Versión en Línea

E-mail: revistacientifica@fce.unam.edu.ar
} 
Asimismo, se dice que desde hace unos años en el turismo hay nuevos perfiles de turistas los cuales han pasado de ser Consumer o turistas clásicos (quienes compran sus paquetes en agencias de viajes físicas y opinan poco del servicio recibido) a los Prosumer o consumidor activo (quienes compran de forma física y online y opinan en redes sociales conocidas y contribuyen al diseño de los productos) y finalmente, los Adprosumer (compran servicios individuales para tener su propia experiencia y opinan influyendo en otros consumidores, mediante blogs videos o fotografías)

Más allá de las características propias de estas dos últimas Generaciones a nivel mundial (según lo describen los libros), la evolución y actualización tecnológica (4G, 5G, redes sociales, etc.), las tendencias generales de la demanda, el contexto socio - económico particular de la Argentina, y el mercado turístico nacional y provincial; se podrían definir particularidades del perfil del turista Millennials y Centennials que visitan Misiones, lo cual se analizará en el trabajo de campo presentado más adelante en este artículo.

En cuanto a la relevancia de estas generaciones en la demanda turística a nivel mundial, se sostiene que hoy día por lo menos el $24 \%$ de los consumidores turísticos son de la Generación Millennials. (https://www.elfinancierocr.com). Por otro lado, en base a una encuesta realizada por Tripadvisor y publicado por la revista Hosteltur de España en el año 2019, las Generaciones Millennials y Centennials tienen la mayor preferencia de viajes alcanzando el $42 \%$, frente al $30 \%$ de los mayores de 37 años. (https://www.hosteltur.com).

En relación a la provincia de Misiones, según el último Estudio de perfil de la demanda turística que hizo el Ministerio de Turismo de Misiones en el verano de 2018, el 42\% de los visitantes de la provincia corresponden a personas de estas dos generaciones y constituye el grupo etario más amplio (https://issuu.com/mkt-mintur-misiones)

\section{Metodología}

Este artículo descriptivo se basa en fuentes secundarias (libros y revistas científicas) y fuentes primarias mediante la concreción de 108 encuestas aplicadas a turistas en Posadas y San Ignacio, provincia de Misiones. Las unidades de observación fueron individuos pertenecientes a las Generaciones Millennials y Centennials (con edades entre 18 y 37 años), quienes compran y usan los servicios turísticos y que visitaron Posadas y San Ignacio, provincia de Misiones, durante la segunda quincena mes de julio (entre el 13 y el 23 en Posadas, y los días 21 y 27 en San Ignacio) del año 2018, mediante un muestreo probabilístico por conglomerados y luego sistemático sin marco muestral, mediante encuestas cara a cara en determinados atractivos (en Posadas en la Bajada Vieja al alcanzar la Avenida Costanera Monseñor Kemerer y en el monumento a Andresito Guacurarí y en San Ignacio a la salida del

\footnotetext{
"Visión de Futuro" Año 18, Volumen N²5 N², Edición Especial-III Congreso Regional de Economía del Norte Grande-Pág 124-144 URL de la Revista: http://visiondefuturo.fce.unam.edu.ar/index.php/visiondefuturo/index

URL del Documento: https://visiondefuturo.fce.unam.edu.ar/index.php/visiondefuturo/issue/view/20

ISSN 1668 - 8708 - Versión en Línea

E-mail: revistacientifica@fce.unam.edu.ar
} 
predio jesuítico guaraní) y a partir de ahí muestreo sistemático (cada quinta persona que salía fue encuestada). El cuestionario de encuesta se compuso de 36 preguntas (26 de una sola respuesta y 10 de respuesta múltiple) y en su amplia mayoría de tipo cerradas. Las dos primeras preguntas aludían a la edad y el lugar de origen, de modo de garantizar su inclusión a la población objeto de estudio.

\section{Resultados de las encuestas}

El 98\% de los Millennials y Centennials (de 18 y más años) que visitan Posadas y San Ignacio buscan información sobre el destino. De ellos, el 53\% lo hace antes y durante el viaje, mientras que el $37 \%$ solo lo hace antes del inicio del mismo. Para ello, utilizan principalmente páginas webs (40\%) seguido por la información disponible en redes sociales y blogs (35\%), empleando como dispositivo de búsqueda, el teléfono celular (60\%), y la computadora personal (33\%).

El 36\% se alojó en el destino. Para el caso particular de la elección del servicio de alojamiento, los encuestados valoran ampliamente (66\%) la opinión de otras personas en portales o plataformas de Internet (Booking, Tripadvisor, redes sociales, etc.). Mientras que para el $29 \%$ es poco o nada importante esta información.

Entre las TIC que utilizan, las redes sociales destacan por la facilidad de uso y la posibilidad de llegar a miles de usuarios. También eligen para planificar y elegir sus vacaciones, como para compartir durante los mismos la experiencia con sus seguidores. En relación al uso que hacen de estas redes sociales (Instagram y Facebook), un alto número de encuestados (84\%) manifiesta hacer comentarios o subir fotos durante su estadía. El 49\% lo realiza una vez al día, y el 30\% cada 3-4 horas. El 83\% de los encuestados responde a los comentarios y/o preguntas de sus seguidores, pero manifiestan no dar mayor importancia a los Like (65\%). El 35\% restante realizan el seguimiento de los Me gusta que poseen. Poco más de la mitad de los encuestados opina de los servicios y de los destinos en sitios de reputación on line, tanto durante el viaje como después del mismo; poco menos de la otra mitad (45\%) expresa no realizar este tipo de posteos.

\footnotetext{
"Visión de Futuro" Año 18, Volumen N²5 N², Edición Especial-III Congreso Regional de Economía del Norte Grande-Pág 124-144 URL de la Revista: http://visiondefuturo.fce.unam.edu.ar/index.php/visiondefuturo/index

URL del Documento: https://visiondefuturo.fce.unam.edu.ar/index.php/visiondefuturo/issue/view/20

ISSN 1668 - 8708 - Versión en Línea

E-mail: revistacientifica@fce.unam.edu.ar
} 


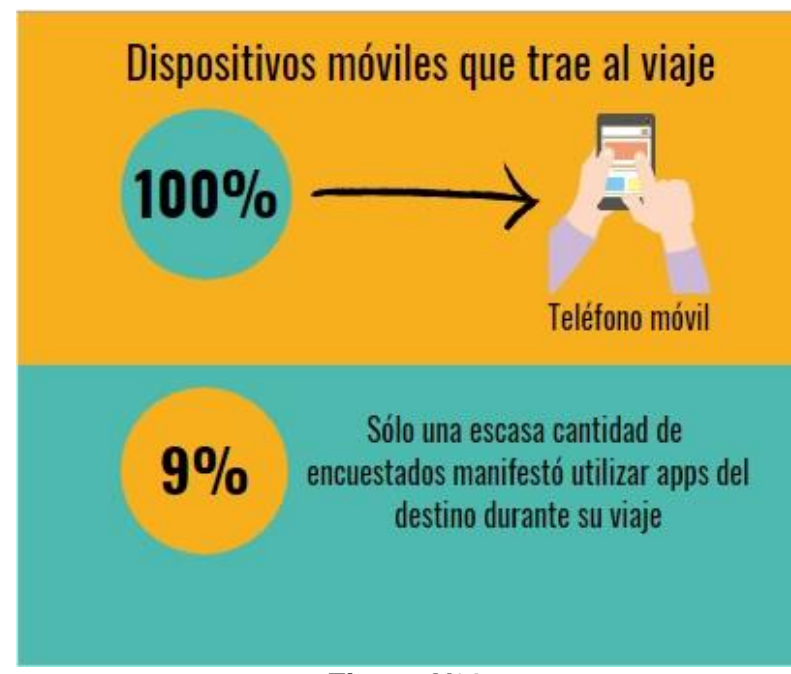

Figura $\mathrm{N}^{\circ} \mathbf{1}$

Fuente: elaboración propia de miembros del proyecto de investigación (Fiorino, Banacor y De Amaral) a partir de encuestas Posadas - San Ignacio. Año 2018

Consultados respecto a qué dispositivos móviles son los que utilizan durante los viajes, la totalidad de los encuestados manifestó viajar con teléfonos celulares. Además, el 12\% lleva tablets y notebook/netbooks. Esto afirma que para los Millennials y Centennials los dispositivos móviles y en especial el Smartphone que son entendidos casi una extensión de su cuerpo, una herramienta rápida, segura y cómoda. Sin embargo, aún con el uso tan frecuente de los celulares, pocos encuestados (9\%) expresó utilizar aplicaciones de los destinos durante su estadía en los mismos.

Respecto a los motivos por los que visitaron Posadas y San Ignacio, se elaboraron los siguientes gráficos:

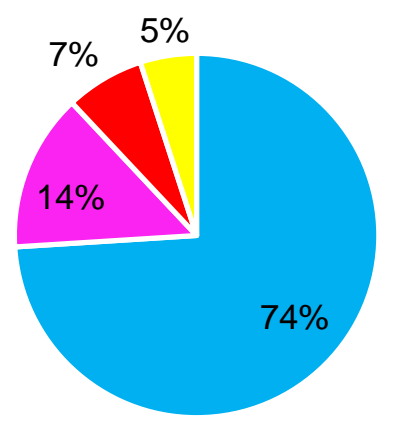

- Turismo. Posadas como etapa de viaje

- Turismo. Posadas como destino final

- Trabajo

Visita a familiares

Gráfico N¹: Motivos de visita a Posadas

Fuente: elaboración propia de miembros del proyecto de investigación (Fiorino, Banacor y De Amaral) a partir de encuestas Posadas - San Ignacio. Año 2018.

\footnotetext{
"Visión de Futuro" Año 18, Volumen No 25 º2, Edición Especial-III Congreso Regional de Economía del Norte Grande-Pág 124-144 URL de la Revista: http://visiondefuturo.fce.unam.edu.ar/index.php/visiondefuturo/index

URL del Documento: https://visiondefuturo.fce.unam.edu.ar/index.php/visiondefuturo/issue/view/20

ISSN 1668 - 8708 - Versión en Línea

E-mail: revistacientifica@fce.unam.edu.ar
} 
En base a este gráfico, se puede observar que el $88 \%$ de los encuestados vino a Posadas por turismo y que el $74 \%$ de ellos consideró a Posadas como una parte/ etapa del viaje, siendo su destino final otras localidades como Iguazú (Argentina) o las playas brasileñas.

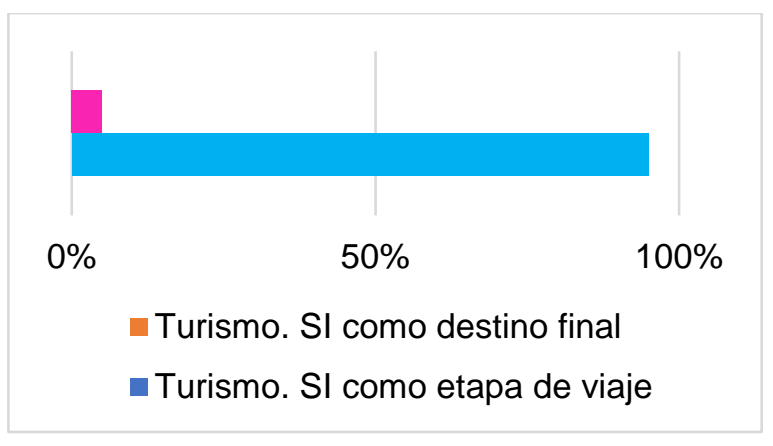

Gráfico $\mathrm{N}^{\circ}$ 2: Motivo de visita a San Ignacio (SI)

Fuente: elaboración propia de miembros del proyecto de investigación (Fiorino, Banacor y De Amaral) a partir de encuestas Posadas - San Ignacio. Año 2018.

Para los encuestados en San Ignacio, el turismo es el único motivo de viaje, correspondiendo como ciudad de paso hacia otro destino final un 95\% y como destino final el $5 \%$.

Se observa que, para ambas localidades, el motivo principal de visita es el del turismo como etapa de viaje. Esto se explica por la poca distancia que tienen Posadas y San Ignacio, del atractivo turístico más importante de turismo regional e internacional, que son las Cataratas del Iguazú.

En cuanto a los factores que influyen al momento de decidir por un destino turístico, los encuestados que visitan las ciudades de Posadas y San Ignacio, consideran al atractivo (con 73 respuestas), los precios (49) y, la opinión de terceros (44 respuestas) como los principales decisores para la elección de un determinado destino.

La mitad de los encuestados prefiere destinos nacionales e internacionales en forma indistinta, mientras que la otra mitad opta por destinos nacionales.

En relación al perfil de estos turistas, se destacan por: lugar de procedencia: mayoritariamente son turistas nacionales $(91 \%)$ y en menor medida $(9 \%)$, extranjeros. Su nivel educativo y tipo de ocupación se puede apreciar en la siguiente figura:

\footnotetext{
"Visión de Futuro" Año 18, Volumen No 25 N², Edición Especial-III Congreso Regional de Economía del Norte Grande-Pág 124-144 URL de la Revista: http://visiondefuturo.fce.unam.edu.ar/index.php/visiondefuturo/index

URL del Documento: https://visiondefuturo.fce.unam.edu.ar/index.php/visiondefuturo/issue/view/20

ISSN 1668 - 8708 - Versión en Línea

E-mail: revistacientifica@fce.unam.edu.ar
} 




Figura $\mathrm{N}^{\circ} 2$

Fuente: elaboración propia de miembros del proyecto de investigación (Fiorino, Banacor y De Amaral) a partir de encuestas Posadas - San Ignacio. Año 2018

En cuanto al perfil de estos visitantes entre 18 y 37 años, se observa un predominio de personas universitarias, ya sea por tener su título o estar estudiando alguna carrera. La mayor parte de ellos trabaja y viajan en familia o en pareja.

Para llegar a la provincia de Misiones utilizaron como medio de movilidad el automóvil particular (55\%), y en menor medida el ómnibus (23\%) y otros medios $(22 \%)$ entre los que se destaca el transporte aéreo, particularmente utilizado entre los encuestados que arribaron a la ciudad de Posadas. El tiempo de duración de los viajes es de una semana (66\%), seguidos por quienes viajan durante más de una semana con el $14 \%$.

La decisión de visitar los destinos de la provincia de Misiones, Posadas y San Ignacio, fue tomada entre la familia (34\%), con la pareja (23\%) y entre el grupo de amigos (20\%)



Gráfico N³: Motivos de la decisión para visitar Posadas- San Ignacio

Fuente: elaboración propia de miembros del proyecto de investigación (Fiorino, Banacor y De Amaral) a partir de encuestas Posadas - San Ignacio. Año 2018.

\footnotetext{
"Visión de Futuro" Año 18, Volumen No 25 N², Edición Especial-III Congreso Regional de Economía del Norte Grande-Pág 124-144 URL de la Revista: http://visiondefuturo.fce.unam.edu.ar/index.php/visiondefuturo/index

URL del Documento: https://visiondefuturo.fce.unam.edu.ar/index.php/visiondefuturo/issue/view/20

ISSN 1668 - 8708 - Versión en Línea

E-mail: revistacientifica@fce.unam.edu.ar
} 
Respecto a la frecuencia de viajes por turismo que hacen por año, se obtuvo el siguiente gráfico:

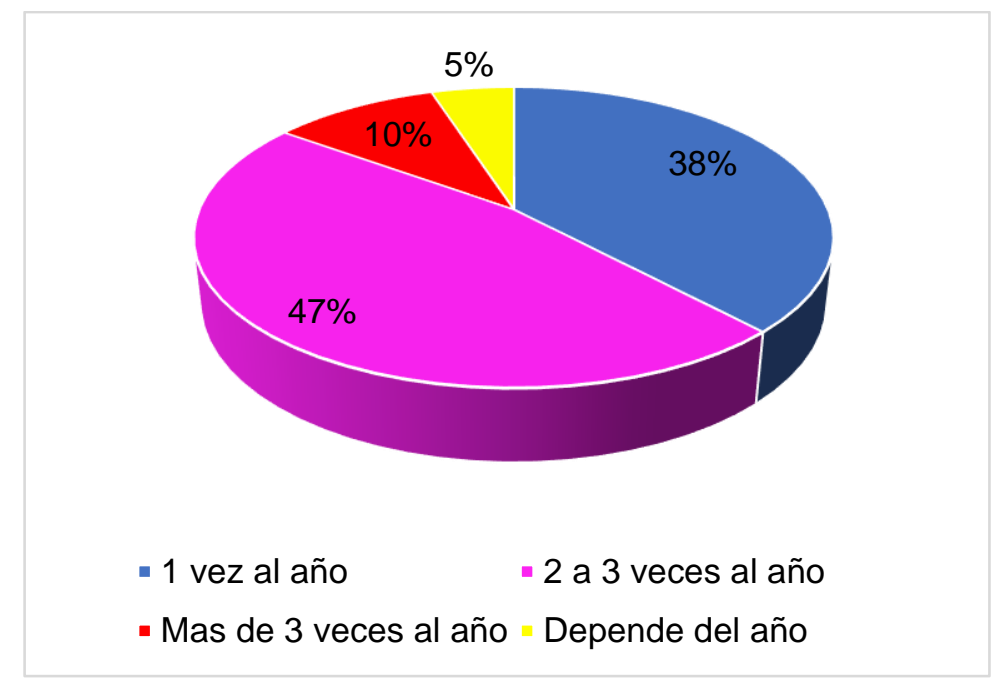

Gráfico №4: Frecuencia de viajes en el año

Fuente: elaboración propia de miembros del proyecto de investigación (Fiorino, Banacor y De Amaral) a partir de encuestas Posadas - San Ignacio. Año 2018.

Se observa que casi la mitad de los encuestados viaja por turismo entre 2 a 3 veces al año, seguido de aquellos que lo hacen 1 sola vez al año.

Tabla №1: Factores que influyen en la elección del destino (respuesta múltiple)

\begin{tabular}{|l|c|}
\hline \multicolumn{1}{|c|}{ Factores } & Porcentaje \\
\hline Información previa disponible & 10,4 \\
\hline Atractivos en destino & 29,5 \\
\hline Precios & 19,7 \\
\hline Accesibilidad (física y comunicacional) & 4,8 \\
\hline Opinión de terceros & 17,6 \\
\hline Actividades en el lugar & 12,8 \\
\hline Seguridad & 2,4 \\
\hline Otros & 2,8 \\
\hline Total & $100 \mathrm{~N}=249$ \\
\hline
\end{tabular}

Fuente: elaboración propia a partir de encuestas Posadas - San Ignacio. Año 2018.

En general, los encuestados eligen los destinos por sus atractivos como ser lugares naturales o de patrimonio inmaterial (fiestas costumbres, tradiciones) y material (edificaciones con historia), que poseen altos estándares de autenticidad y en contacto con las comunidades locales, seguido por su precio (tarifas) y la opinión de terceros (Booking)

\footnotetext{
"Visión de Futuro" Año 18, Volumen No 25 N², Edición Especial-III Congreso Regional de Economía del Norte Grande-Pág 124-144 URL de la Revista: http://visiondefuturo.fce.unam.edu.ar/index.php/visiondefuturo/index

URL del Documento: https://visiondefuturo.fce.unam.edu.ar/index.php/visiondefuturo/issue/view/20

ISSN 1668 - 8708 - Versión en Línea

E-mail: revistacientifica@fce.unam.edu.ar
} 
Con estos datos se puede decir que el perfil de los visitantes de la provincia de Misiones que tienen entre 18 y 37 años coincide con el perfil turístico general de estas dos Generaciones a nivel mundial. Si bien actualmente en la provincia de Misiones tenemos visitantes y turistas de las generaciones $X, Y$ y $Z$, las dos últimas están: 1. más informados antes de viajar, 2. más conectados, que comparten y opinan, 3. más experimentados, exigentes y críticos y, 4. que buscan experiencias memorables y 5 . hacer un turismo activo y auténtico.

\section{Las nuevas generaciones y la gestión empresarial}

En base a estas características y datos de consumo turístico de las nuevas generaciones, las empresas necesitan adaptarse a estas particularidades.

Para ello, se deben tener en cuenta dos cuestiones: 1. actualmente, según el Observatorio $\mathrm{ORH}$, el $59 \%$ de la fuerza laboral corresponde a las Generaciones Millennials y Centennials (https://www.observatoriorh.com) y, 2. según Matías Ortega, en las empresas los trabajadores Millennials y Centennials conviven con Generaciones anteriores como los X y muchas veces también con los Baby Boomers, quienes frecuentemente dirigen la organización, y la convivencia intergeneracional debe darse de tal manera que se puedan atender las nuevas necesidades y motivaciones de las generaciones $Y$ y $Z$, quienes buscan la flexibilidad y cambian frecuentemente la empresa en la que trabajan (https://www.ambito.com)

En función de estos perfiles Millennials y Centennials, Hatun (2013) dice que las organizaciones deberían permitir horarios y actividades laborales flexibles, incorporar actividades laborales en la vida cotidiana, incorporar redes sociales al trabajo, crear un ambiente laboral más dinámico y multitarea, mayor trabajo en equipo, una estructura más plana y más conectada en red, el uso extendido de tecnologías y elección personal de las mismas, participar de la toma de decisiones, énfasis en la responsabilidad social empresaria, entre otros aspectos.

Por otro lado, estas dos nuevas generaciones - que son las que actualmente más consumen y hacen turismo- se debe adecuar la oferta turística, la cual según ITB World Travel Trends Report y Fitur (2015) debe ser:

- Basada en el uso y accesibilidad a las redes sociales, ya que contamos con pasajeros digitales (facebook para los Millennials e Instagram para Centennials)

- La oferta debe basarse en la simplicidad y experiencia.

- Incorporar nuevos y más espacios de socialización.

- Los paquetes deben ser dinámicos y adaptables.

\footnotetext{
"Visión de Futuro" Año 18, Volumen No 25 N², Edición Especial-III Congreso Regional de Economía del Norte Grande-Pág 124-144 URL de la Revista: http://visiondefuturo.fce.unam.edu.ar/index.php/visiondefuturo/index

URL del Documento: https://visiondefuturo.fce.unam.edu.ar/index.php/visiondefuturo/issue/view/20

ISSN 1668 - 8708 - Versión en Línea

E-mail: revistacientifica@fce.unam.edu.ar
} 
- Proponer más financiación y reservas anticipadas.

-Más conciencia ambiental y protección de la identidad local

- Incentivar nuevas modalidades de turismo como el turismo colaborativo, turismo de nicho, turismo de salud y bienestar, del turismo cultural al creativo,

- Incrementar la experiencia y lo auténtico, que se relaciona con una redefinición del lujo.

En este sentido, la revista digital Hosteltur (2017) identifica nuevos mercados emisores de turismo a nivel mundial de estas generaciones: Reino Unido, Suiza, Polonia, Rusia, China, Alemania, etc., con culturas y costumbres diferentes entre ellos. Finalmente, para Dieckow y Lansse (2017) la llamada Economía naranja o Economía creativa, que se basa en la articulación entre el capital cultural, social e intelectual adquiere cada vez más importancia para motivar y satisfacer a estas dos generaciones.

Como los miembros de estas dos generaciones son personas independientes, suelen armar sus propios viajes y paquetes turísticos, por lo que usan plataformas como Booking y Agencias online (OTAs) como Despegar. Por ello, las empresas que quieran captar estas generaciones deben tener ofertas adaptadas para ellos, que sean flexibles, personalizadas y con alta consideración de la sustentabilidad ambiental y las culturas locales.

Es necesario destacar que, actualmente las empresas que se adapten a los requerimientos de la Generación Millennials y Centennial tienen ante sí una gran oportunidad, ya que conviven en el mercado los turistas de las Generaciones X, Y y Z, y es necesario aprovechar el momento para ajustar, adaptarse e innovar, ya que pronto las Generaciones Millennials y Centennials serán las más importantes en el mercado turístico y exigirán servicios en base a sus motivaciones e intereses.

\section{CONCLUSIONES}

La Tercera Revolución Industrial o Revolución científico - tecnológica genera cambios en las comunicaciones y en el acceso y uso de la información que ha llevado a un nuevo paradigma económico y tecnológico. Las dos últimas generaciones (Millennials y Centennials) exigen cambios en la gestión de las empresas y en la demanda de ofertas turísticas que conlleva a que las empresas deban adatarse y ajustarse al perfil, motivaciones e intereses de estas dos nuevas generaciones para poder sostenerse y tener continuidad a lo largo del tiempo. La oferta turística y las empresas en general deben estar comprometidas con el cuidado del ambiente y las identidades locales. La adaptación a sus intereses lleva a una gestión empresarial con mayor flexibilidad, búsqueda de excelencia, trato personalizado y por

\footnotetext{
“Visión de Futuro" Año 18, Volumen N²5 N², Edición Especial-III Congreso Regional de Economía del Norte Grande-Pág 124-144 URL de la Revista: http://visiondefuturo.fce.unam.edu.ar/index.php/visiondefuturo/index

URL del Documento: https://visiondefuturo.fce.unam.edu.ar/index.php/visiondefuturo/issue/view/20

ISSN 1668 - 8708 - Versión en Línea

E-mail: revistacientifica@fce.unam.edu.ar
} 
supuesto, orientados al logro de experiencias memorables (significativas) y conscientes social y ambientalmente.

\section{REFERENCIAS BIBLIOGRAFICAS}

AIRBNB (17/04/17). Disponible en https://www.airbnb.com.ar AIRDNA (17/04/2016). Disponible en: https://www.airdna.co.

Bilinkis, S. (2014). Pasaje al futuro. Buenos Aires, Argentina. Sudamericana.

Bordas, E. (13/09/2020). "Hacia el turismo de la sociedad de ensueño: nuevas necesidades de mercado". Recuperado de: https://www.uoc.edu/dt/20219/

Cañigeral Bagó, A. (2014). Vivir mejor con menos. Descubre las ventajas de la nueva economía colaborativa. Barcelona. Editorial Conecta. Recuperado de: http://www.rebelion.org/docs/205643.pdf

Caraher, L. (2016). Millennials en la oficina. Como lidiar con una generación que no sigue las reglas. Buenos Aires, Argentina. Editorial Paidós.

Dieckow, L., Lansse, E. (2017). La problemática económica del turismo II. Un abordaje teórico, aplicado y práctico. Posadas, Argentina. EDUNaM - Editorial Universitaria de la Universidad Nacional de Misiones.

Dieckow, L., Lansse, E. (2020). LOS MILLENNIALS Y EL TURISMO. Análisis de las particularidades de esta generación en relación al consumo turístico, su percepción sobre la calidad, y su desempeño como profesional, en función de su formación, inserción laboral y Emprendedurismo. Proyecto de investigación. Integrantes: F. Fiorino, C. Castells, A. Maciel, M. Groh, C. Balustra, F. Banacor, F. Palucito, H. De Amaral, F. Pérez Levitt Código: 16H/493. Secretaría de Investigación y Postgrado. Facultad Humanidades y Ciencias Sociales. UNaM. Período 2018-2020.

El financiero (05/08/2017). "Millennials: nuevos dueños y señores del mundo". Recuperado de: https://www.elfinancierocr.com/opinion/millennials-nuevos-duenos-y-senores-delmundo/GIUEL2ZXKVC5NM3MUVLWHY2GF4/story/10/03/2019

Forbes (10/12/16). "6 rasgos clave de los Millennials, los nuevos consumidores". Recuperado de: $\quad$ http://www.forbes.com.mx/6-rasgos-clave-de-los-millennials-losnuevosconsumidores/\#gs.C7ttqvk

Hatum, A. (2013). Yrrupción. Los cambios generacionales y el futuro de la organización. Buenos Aires. Argentina. Temas grupo editorial.

Hidalgo, O. (18/09/2020). "Millennials: nuevos dueños y señores del mundo”. Recuperado de: https://www.elfinancierocr.com/opinion/millennials-nuevos-duenos-y-senores-delmundo/GIUEL2ZXKVC5NM3MUVLWHY2GF4/story/

\footnotetext{
"Visión de Futuro" Año 18, Volumen No 25 N², Edición Especial-III Congreso Regional de Economía del Norte Grande-Pág 124-144 URL de la Revista: http://visiondefuturo.fce.unam.edu.ar/index.php/visiondefuturo/index

URL del Documento: https://visiondefuturo.fce.unam.edu.ar/index.php/visiondefuturo/issue/view/20

ISSN 1668 - 8708 - Versión en Línea

E-mail: revistacientifica@fce.unam.edu.ar
} 
Hosteltur

$(07 / 02 / 2017)$

"Noticias

de

turismo"

Recuperado

de:

http://www.hosteltur.lat/117430_alojamientosairbnb-argentina-aumentaron-502015.html

HOSTELTUR (14/01/2019). "Informe de TripAdvisor. Tendencias de los viajes en 2019 por edad y nacionalidad" Recuperado de:https://www.hosteltur.com/126132_tendencias-delos-viajes-en-2019-por-edad-y-nacionalidad.html

Kuklinski, H. (11/02/17). "10 libros imprescindibles para entender el futuro de la economía digital”. Recuperado de: http://digitalismo.com/10librosimprescindibles-paraentender-elfuturo.

Ministerio de Turismo de Misiones (28/05/2018). "Estudio del perfil del turista verano 2018. Misiones, Argentina". Recuperado de: https://issuu.com/mkt-minturmisiones/docs/estudio_perfil_turista_verano_2018,2/01/2021

Mora Simoes, D. (2017). Cómo cazar a un Millennial. Mitos y verdades sobre los jóvenes y su relación con el trabajo. Buenos Aires, Argentina. Ediciones B.

Naviera, A. (21/10/2019). "Así son los Centennials: la generación que está revolucionando la forma de hacer marketing y vender". Recuperado de: https://marketing4ecommerce.net/los-centennials-la-generacion-digital-mas-experta-lahistoria/

ORH Observatorio de RRHH (28/01/2020). "Los Millennials y Centennials ya representan el $59 \%$ de la fuerza de trabajo". Recuperado de: https://www.observatoriorh.com/orhposts/los-millennials-y-centennials-ya-representan-el-59-de-la-fuerza-de-trabajo.html

Ortega, M. (15/082018). "Las cuatro generaciones en las empresas" Recuperado de: https://www.ambito.com/edicion-impresa/las-cuatro-generaciones-las-empresasn4030610

Red Argentina de destinos turísticos inteligentes (18/09/2020). Recuperado de: www.reddti.ar.com.ar

Rifkin, J. (2011). La tercera revolución industrial. España. Paidós.

Rifkin, J. (2014). La sociedad de coste marginal cero. España, Paidós.

UBER (17/04/2016). Disponible en: http://www.uberenargentina.com.ar.

\section{RESUMEN BIBLIOGRÁFICO}

\section{Liliana María Dieckow}

Licenciada en turismo. Magister en Administración estratégica de negocios y Doctora en Administración (UNaM). Profesor asociado regular, dedicación exclusiva en FHyCS- UNaM (Posadas Argentina). Investigador Categoría I. Director de proyectos de investigación (PDTS) vinculados con el turismo, administración y el desarrollo económico. Autor y co autor de varios libros.

\footnotetext{
"Visión de Futuro" Año 18, Volumen No 25 º2, Edición Especial-III Congreso Regional de Economía del Norte Grande-Pág 124-144 URL de la Revista: http://visiondefuturo.fce.unam.edu.ar/index.php/visiondefuturo/index

URL del Documento: https://visiondefuturo.fce.unam.edu.ar/index.php/visiondefuturo/issue/view/20

ISSN 1668 - 8708 - Versión en Línea

E-mail: revistacientifica@fce.unam.edu.ar
} 